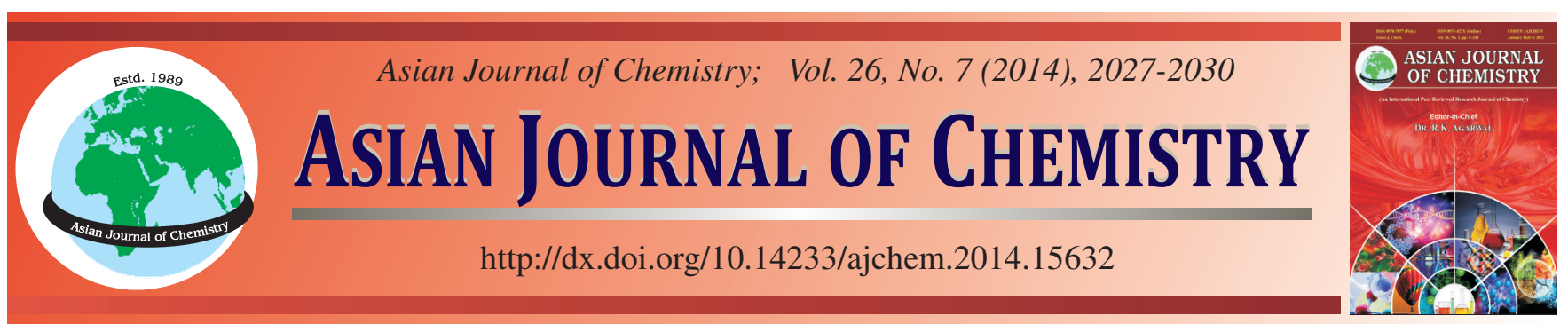

\title{
Liquid-Liquid Microextraction with Vortex-Assisted for Determination of Palladium and Gold in Water Samples by Flame Atomic Absorption Spectrometry
}

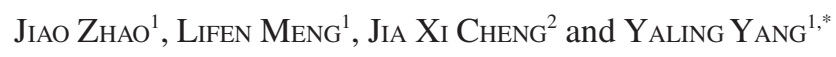

${ }^{1}$ Faculty of Life Science and technology, Kunming University of Science and Technology, Kunming 650500, Yunnan Province, P.R. China ${ }^{2}$ Yunnan Metallurgy Group Co. Ltd., Kunming 650031, Yunnan Province, P.R. China

*Corresponding author: Tel: +86 13888316388; E-mail: yilyil8@163.com

In this research, a novel method is described for the determination of traces of palladium and gold in water samples by vortex-assisted liquid-liquid microextraction (VA-LLME) prior to flame atomic absorption spectrometry (FAAS) analysis. Palladium and gold reacted with diethyldithiocarbamate (DDTC) forming hydrophobic chelates (M-DDTC), which were extracted efficiently into pelargonic acid after vortex-mixing and centrifuging. The effects of experimental conditions concerning $\mathrm{pH}$ of sample solution, concentration of chelating agent, types and concentration of extraction solvent and emulsifying strength were evaluated and optimized. Under the optimal conditions, the calibration graph are linear in the range of $10-500 \mu \mathrm{g} \mathrm{L}^{-1}$, with the correlation coefficients $\left(\mathrm{r}^{2}\right)$ more than 0.9950 . The low limits of detection for palladium and gold were 2.4 and $1.6 \mu \mathrm{g} \mathrm{L}^{-1}$, respectively. The recoveries ranged from 96.77 to $97.18 \%$ and the relative standard deviations (RSD) were between 0.7 and $1.8 \%(n=6)$. The method was successfully applied to the analysis of palladium and gold in water samples.

Keywords: Palladium, Gold, Diethyldithiocarbamate, Liquid-liquid microextraction, FAAS, Vortex-assisted, Pelargonic acid.

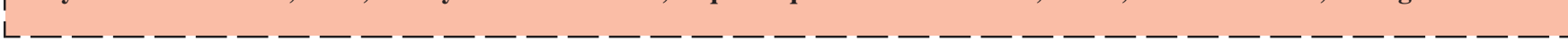

\section{INTRODUCTION}

The significance of the palladium metal has grown in today's industries due to the increasing applications for the production of dental and medicinal devices, jewellery, automobile and catalytic converters. The emission of $\mathrm{Pd}(\mathrm{II})$ into the environment is largely associated with the production and recycling of catalytic converters in the metal finishing industry as well as the operation of vehicle catalysts ${ }^{1-4}$. In this way, they can be dissolved in soil, water and plant. Then they can enter into the food chain ${ }^{5}$. Moreover, some of Pd compounds have been reported as potential health risks to humans, causing asthma, allergy, conjunctivitis and other serious health problems ${ }^{6-8}$. Gold belongs to the group of elements which occurs on the earth in very low concentration. It is valuable metal for its attractive physical and chemical character and wide range of applications such as in biomedicine, automatics, jewelry, chemical industry, energy and process technology. Gold in environment can also affect living organisms and human health ${ }^{9,10}$. Thus, procedures of separation or preconcentration may be required before the spectrometric determination of trace elements ${ }^{11,12}$.

The precious metals occur in geological materials at trace and ultratrace levels and their direct determination is beyond the scope of atomic absorption spectrometry (AAS), induc- tively coupled plasma optical emission spectrometry (ICPOES) and graphite furnace atomic absorption spectrometry (GFAAS). Therefore, low concentration of analytes and matrix effects are often required a suitable sample pretreatment step. Techniques such as co-precipitation ${ }^{13}$, solid phase extraction ${ }^{14-16}$, cloud point extraction ${ }^{17,18}$ and liquid-liquid extraction ${ }^{19,20}$ are widely used in the separation and preconcentration of trace elements. These preconcentration methods have attributed to improve the sensitive and efficiency in environmental samples.

In this study, we put forward a more sensitive and economical methods for determination of trace amounts of palladium and gold, which is called vortex-assisted liquid-liquid microextraction (VA-LLME). Liquid-liquid micro-extraction (LLME) is a classical extraction and separation technique, combined with vortex-mixing, the mixture emulsify completely. After centrifuging, the solution is separated into two phases: a water phase and an organic phase containing a high metal complex in a small volume. VA-LLME could avoid using toxic organic solvents ${ }^{21}$ that were volatile and achieve a much higher recovery of rare metal ions through a small volume of the extraction agent.

The main results obtained in optimization studies, analytical features evaluation and analysis of real water samples are presented and discussed. 


\section{EXPERIMENTAL}

A 6300C atomic absorption spectrometer (AAS) (Shimadzu, Japan) with acetylene flame and hallow cathode lamps was used for the determination of metal ions. The operating conditions are given in Table-1. A pH meter, Elico Li-129 model glass-calomel combined electrode (Shanghai, China) was employed for measuring $\mathrm{pH}$ values. A vortex mixing apparatus (Shanghai, China) was prepared for assisting the mixture emulsifying. A centrifuge with calibrated centrifugal tubes (Shanghai, China) was used for the phase separation process.

\begin{tabular}{lcc}
\multirow{2}{*}{ TNSTRUMENTAL PARAMETERS FOR FAAS } \\
\hline \multirow{2}{*}{ Condition } & \multicolumn{2}{c}{ Numberical value } \\
\cline { 2 - 3 } & $\mathrm{Pd}$ & $\mathrm{Au}$ \\
\hline Analytical wavelength $(\mathrm{nm})$ & 247.6 & 242.8 \\
Lamp current $(\mathrm{mA})$ & 15 & 10 \\
Spectral band pass $(\mathrm{nm})$ & $0.7 \mathrm{~L}$ & $0.7 \mathrm{~L}$ \\
\hline
\end{tabular}

Stock standard solution $\left(1000 \mu \mathrm{g} \mathrm{mL}^{-1}\right)$ of $\mathrm{Pd}$ and Au were purchased from China National Institute of Standards (Beijing, China). The pelargonic acid with $98 \%$ purity was from Aladdin (Guangzhou, China). All the reagents used were analytical reagent grade. Deionized double distilled water was used throughout.

$500 \mu \mathrm{g} \mathrm{mL} \mathrm{m}^{-1}$ of diethyl dithiocarbamate (DDTC) (Shanghai, China) was prepared by dissolving in double distilled water. Ammonium buffer solutions were prepared by mixing of appropriate amounts of ammonia and ammonium chloride solutions for $\mathrm{pH} 10$.

Laboratory glassware was kept overnight in a $10 \%(\mathrm{v} / \mathrm{v})$ $\mathrm{HNO}_{3}$ solution and then rinsed with deionized double distilled water.

Experimental procedure: $120 \mu \mathrm{L}$ of diethyl dithiocarbamate $\left(500 \mu \mathrm{g} \mathrm{mL}^{-1}\right)$ was added in $10 \mathrm{~mL}$ of the sample or standard solution ( $\mathrm{pH} \mathrm{5)} \mathrm{containing} \mathrm{the} \mathrm{analyte} \mathrm{for} 5 \mathrm{~min}$, following $0.6 \mathrm{~mL}$ pelargonic acid was added. Then, the mixture was vortex-mixed for $30 \mathrm{~s}$ and centrifuged at $3000 \mathrm{rpm}$ for $5 \mathrm{~min}$. The mixture was separated into two phases and the pelargonic acid floated on the solution. The aqueous phase was carefully removed by using a syringe with a long needle. And the pelargonic acid phase was diluted to $500 \mu \mathrm{L}$ with methanol, finally determined by flame atomic absorption spectometer.

Pretreatment of real samples: The samples of water were derived from local industrial sewage and then digested with $2 \mathrm{~mL} \mathrm{HCl}\left(1.179, \mathrm{~g} \mathrm{~L}^{-1}\right), 2 \mathrm{~mL} \mathrm{HNO}_{3}\left(1.405, \mathrm{~g} \mathrm{~L}^{-1}\right)$ in electric hot plate digestion system and diluted to $10 \mathrm{~mL}$ with deionized water. A blank sample was treated in the same way.

\section{RESULTS AND DISCUSSION}

Effect of pH: It is obvious that $\mathrm{pH}$ plays a unique role on the metal-chelate formation and its subsequent extraction. So, the influence of $\mathrm{pH}$ on the extraction of hydrophobic chelate of Pd-DDTC and Au-DDTC from $10 \mathrm{~mL}$ of aqueous phase into $200 \mu \mathrm{L}$ pelargonic acid was studied for the $\mathrm{pH}$ range of 3.0-9.0. Depending on the desired $\mathrm{pH}$, the solutions were buffered by mixtures of phosphoric acid, formic acid and acetic acid with sodium hydroxide. As can be seen in Fig. 1, with the

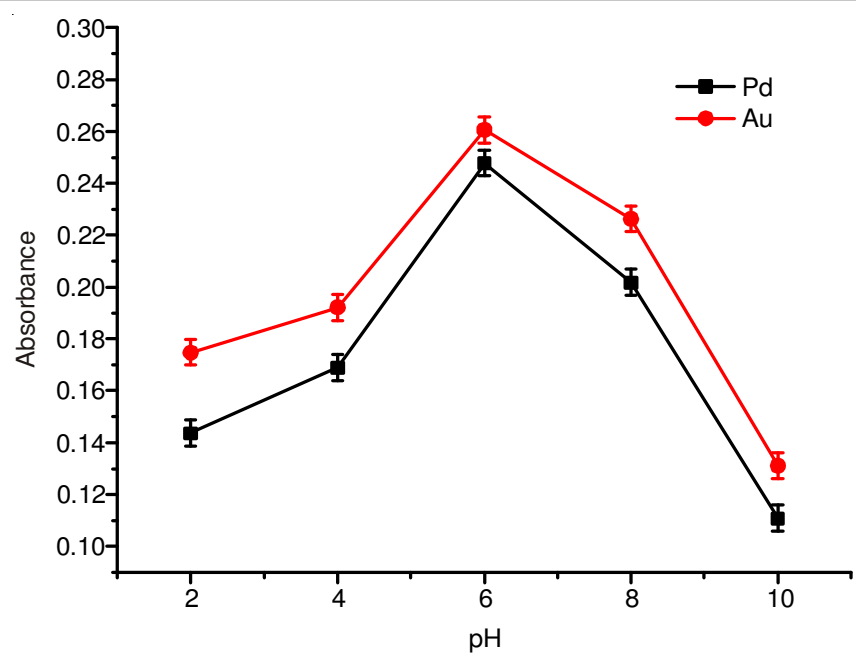

Fig.1. Effect of $\mathrm{pH}$

increase of $\mathrm{pH}$, the highest efficiency was achieved at the $\mathrm{pH}$ 5. So $\mathrm{pH} 5$ was chosen as optimum $\mathrm{pH}$ in the subsequent work.

Effect of diethyl dithiocarbamate concentration: Diethyldithiocarbamate can chelate with metal ions to form coordination compound in which its imino group and the hydroxyl group so as to form a heterocyclic ring containing a metal atom. Only when forming the hydrophobic compounds, can the metal ions can be extracted into pelargonic acid. The concentration of chelating agent is important factor to complexation. The concentration of DDTC ranged between 1 to $10 \mu \mathrm{g} \mathrm{mL}^{-1}$ was studied. The results have been shown in Fig. 2. With the increase of concentration of DDTC, absorbance increase gradually, the optimal absorbance is $6 \mu \mathrm{g} \mathrm{mL} \mathrm{m}^{-1}$. Therefore, $6 \mu \mathrm{g} \mathrm{mL}{ }^{-1}$ DDTC was chosen for further studies.

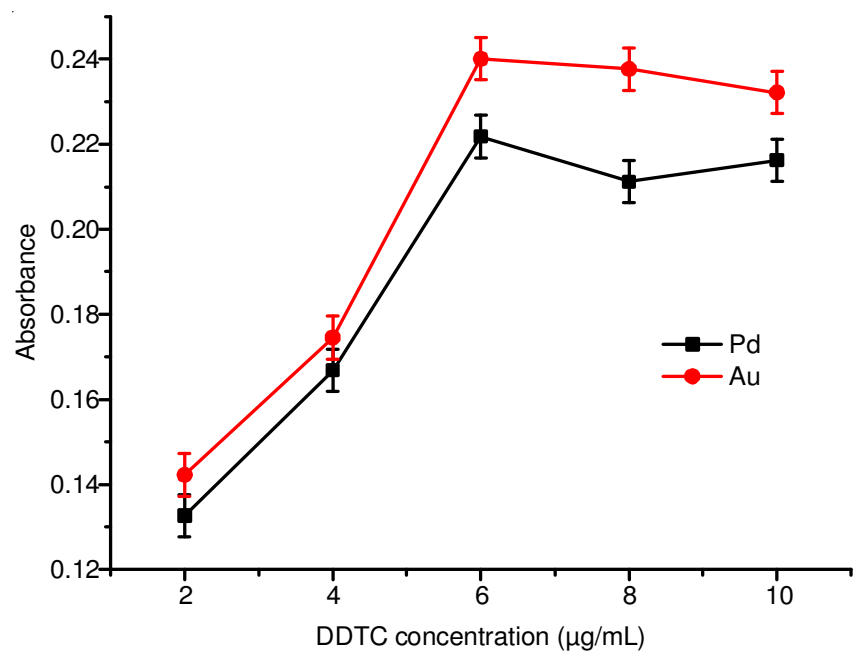

Fig. 2. Effect of chelating ligand concentration

Selection of extraction solvent: Organic acids and organic alcohols are traditional extraction solvent and most frequently used to extract organics experiments. According to the complex of palladium and gold chelate with DDTC, the proper organic acids and organic alcohols to match the polarity were chosen. Organic acids and organic alcohols were novelty used for extracting metal ions. And contrast experiments of the four kinds of extraction solvents were investigated. As shown in Fig. 3, it can be seen that compared octyl alcohol 


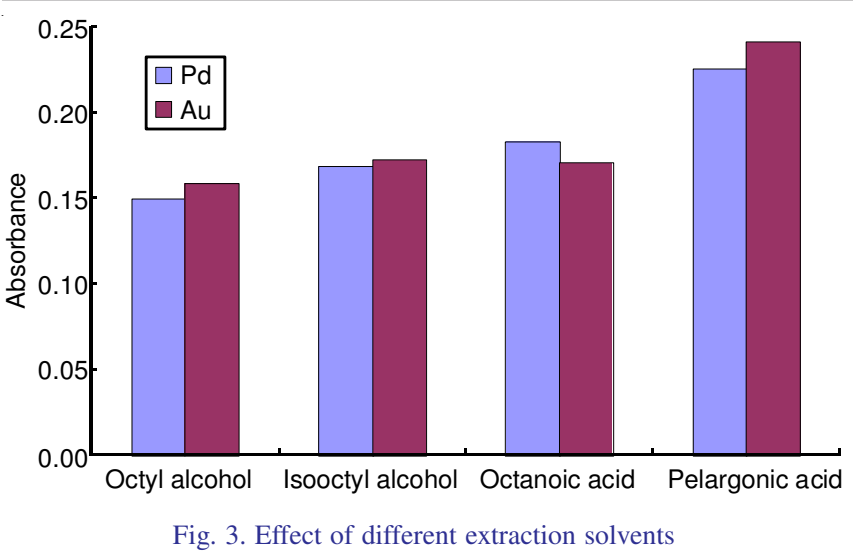

and isooctyl alcohol, octanoic acid and pelargonic acid for extracting solvent. Under the same volume, pelargonic acid obtained the best extraction effect.

Effect of pelargonic acid concentration: An available LLME would maximize the enrichment factor through minimizing the phase volume ratio and the pelargonic acid concentration. The pelargonic acid concentration range from 2 to $10 \%$ $(\mathrm{v} / \mathrm{v})$. Based on the measured absorbance of Pd and Au, Fig. 4 demonstrated that the signal is maximum value as the pelargonic acid volume fraction is $6 \%(\mathrm{v} / \mathrm{v})$ for Pd and Au. The analytical signal decreased at concentration higher than $10 \%(\mathrm{v} / \mathrm{v})$, it might due to the increase of the pelargonic acid volume, solution viscosity amplifies, but against metal complex into photogenic, the comprehensive consideration of the extraction effect and enrichment, so pelargonic acid concentration $6 \%$ $(\mathrm{v} / \mathrm{v})$ is chosen for experiment.

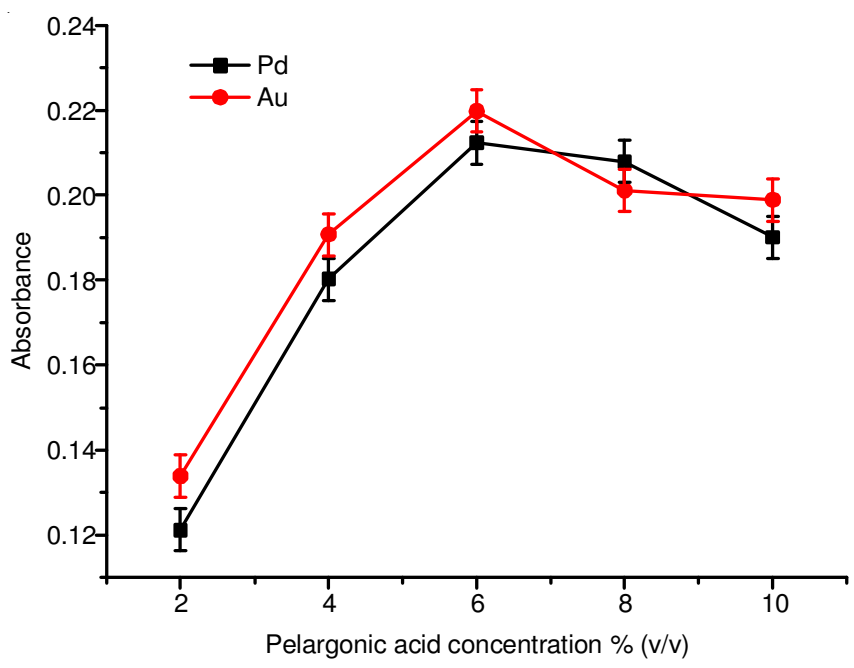

Fig. 4. Effect of pelargonic acid concentration

Comparison of different auxiliary extraction methods: In order to emulsify the mixture sufficient, three assistedextraction means including shaking by hand, vortex-mixing, ultrasound were attempted. The results indicated that vortexmixing achieve optimal extraction efficiency (Fig. 5).

This phenomenon may be explained as follows. Compared with the conventional LLME process, the vortex-mixing process accelerates pelargonic acid molecules attracting each other to form clusters with metal ion complex. However shaking by hand can't emulsify the mixture completely and through ultrasound made the homogeneous phase forming easily, it was hard to be separated into two phases, so lead to the low extraction efficiency.

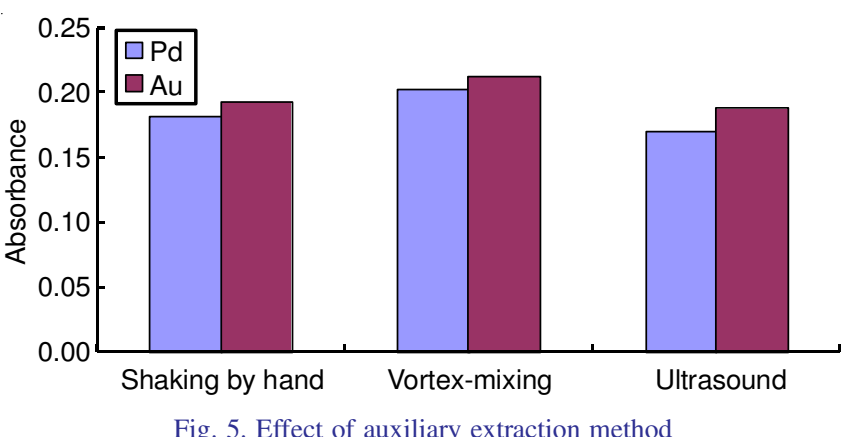

Effect of foreign ions: The effect of other ions in the extraction of Pd and Au was studied under optimized conditions. Because cations may react with DDTC and lead to the decrease of extraction efficiency, $10 \mathrm{~mL}$ of sample solution containing Pd and $\mathrm{Au}$ and other ions were prepared and treated with the developed procedure. The tolerance limit was defined as the foreign ion concentration causing a change in the absorbance of less than $\pm 5 \%$. The results are shown in Table- 2 .

TABLE-2

TOLERANCE LIMITS FOR THE DETERMINATION

\begin{tabular}{lc}
\multicolumn{1}{c}{ Ions } & Interfering ion to analyte ratio \\
\hline $\mathrm{K}^{+}, \mathrm{Na}^{+}, \mathrm{Ca}^{2+}, \mathrm{Mg}^{2+}$ & 2500 \\
$\mathrm{Al}^{3+}, \mathrm{Fe}^{3+}, \mathrm{Mn}^{2+}$ & 1500 \\
$\mathrm{Hg}^{2+}, \mathrm{Cr}^{3+}$ & 1000 \\
$\mathrm{Cd}^{2+}, \mathrm{Ni}^{2+}, \mathrm{Co}^{2+}, \mathrm{Zn}^{2+}$ & 800 \\
$\mathrm{Cl}^{-}, \mathrm{HCO}_{3}, \mathrm{SO}_{4}^{2-}, \mathrm{PO}_{4}^{3-}$, & 2000 \\
$\mathrm{NO}_{3}{ }^{3-}, \mathrm{CH}_{3} \mathrm{COO}^{-}$ & 1500 \\
\hline
\end{tabular}

Determination of Pd and Au in water samples: In order to establish the validity of the established procedure, the method was applied to determine the $\mathrm{Pd}$ and $\mathrm{Au}$ in tap and river water samples. $10 \mathrm{~mL}$ of each of the samples were preconcentrated via the proposed procedure. The recovery experiments for different amounts of Pd and Au were performed. The results are shown in Table-3. The results indicate that the recoveries in the range of 96-102.5\% are reasonable well for trace analysis.

Accuracy and applications: Under the optimum conditions, the calibration graphs were linear in the range 10-500 $\mu \mathrm{g} \mathrm{L}^{-1}$ with coefficients $\left(\mathrm{r}^{2}\right)$ more than 0.9950 and recoveries over 0.960 . The limit of detection (LOD), based on a signalto-noise ratio $(\mathrm{S} / \mathrm{N})$ of 3 , were 2.4 and $1.6 \mu \mathrm{g} \mathrm{L}{ }^{-1}$ respectively. The precision of this method was determined by analyzing standard solution at $1.0 \mu \mathrm{g} \mathrm{L}^{-1}$ of Pd and Au for six times in continuous and the relative standard deviation (RSD) were 0.7 and 1.8. The enrichment factors were 21 and 18 of Pd and $\mathrm{Au}$ for $10 \mathrm{~mL}$ sample solution. The analytical characteristics of the method were shown in Table-4.

Compared the characteristic data of the proposed method with other preconcentration methods for Pd and Au reported in literatures in Table-5. The proposed method possesses lower limit of detection and shorter extraction time than the reported methods with only $10 \mathrm{~mL}$ sample solution and is suitable for 


\begin{tabular}{|c|c|c|c|c|c|c|}
\hline \multicolumn{7}{|c|}{$\begin{array}{c}\text { TABLE-3 } \\
\text { DETERMINATION OF Pd AND Au IN WATER SAMPLES }\end{array}$} \\
\hline \multirow{2}{*}{ Samples } & \multicolumn{2}{|c|}{ Added $\left(\mu \mathrm{g} \mathrm{L}^{-1}\right)$} & \multicolumn{2}{|c|}{ Found $\left(\mu \mathrm{g} \mathrm{L}^{-1}\right)$} & \multicolumn{2}{|c|}{ Recovery $(\%)(\mathrm{n}=6)$} \\
\hline & $\mathrm{Pd}$ & $\mathrm{Au}$ & $\mathrm{Pd}$ & $\mathrm{Au}$ & $\mathrm{Pd}$ & $\mathrm{Au}$ \\
\hline \multirow{3}{*}{ Tap Water } & 0 & 0 & ND & ND & ND & ND \\
\hline & 10 & 10 & 9.7 & 9.6 & 97 & 96 \\
\hline & 20 & 20 & 20.5 & 19.8 & 102.5 & 99 \\
\hline \multirow{3}{*}{ River Water } & 0 & 0 & ND & ND & ND & ND \\
\hline & 10 & 10 & 9.8 & 9.6 & 98 & 96 \\
\hline & 20 & 20 & 19.9 & 19.3 & 99.5 & 96.5 \\
\hline
\end{tabular}

\begin{tabular}{ccccccc} 
& \multicolumn{7}{c}{ TABLE-4 } \\
\hline Element & $\begin{array}{c}\text { Enrichment } \\
\text { factor }\end{array}$ & $\begin{array}{c}\text { Limit of detection } \\
\left(\mu \mathrm{gL}^{-1}\right)\end{array}$ & $\begin{array}{c}\text { RSD \% } \\
\mathrm{n}=6\end{array}$ & $\begin{array}{c}\text { Linear range }\left(\mu \mathrm{g} \mathrm{L} \mathrm{L}^{-1}\right) \\
\left.(\mu \mathrm{g} \mathrm{L})^{-1}\right)\end{array}$ & $\begin{array}{c}\text { Recovery \% } \\
\mathrm{n}=6\end{array}$ & $\begin{array}{c}\text { Regression } \\
\text { equation }\end{array}$ \\
\hline $\mathrm{Pd}$ & 21 & 2.4 & 0.7 & $10-500$ & 96.77 & $\mathrm{y}=0.00285 \mathrm{x}+0.00307$ \\
$\mathrm{Au}$ & 18 & 1.6 & 1.8 & $10-500$ & 97.18 & $\mathrm{y}=0.003286 \mathrm{x}-0.0041$ \\
\hline
\end{tabular}

\begin{tabular}{|c|c|c|c|c|c|}
\hline \multicolumn{6}{|c|}{$\begin{array}{c}\text { TABLE-5 } \\
\text { COMPARIONS OF THE PROPOSED METHOD WITH OTHER SAMPLE } \\
\text { PREPARATION TECHNIQUES FOR THE DETERMINATION OF Pd AND Au }\end{array}$} \\
\hline Method & $\mathrm{LR}\left(\mu \mathrm{g} \mathrm{L}^{-1}\right)$ & $\operatorname{LOD}\left(\mu \mathrm{g} \mathrm{L}^{-1}\right)$ & $\operatorname{RSD}(\%)$ & Extraction time & References \\
\hline DLLME-FAAS & $100-2000$ & $60-90$ & $<0.7$ & $>15 \mathrm{~min}$ & 22 \\
\hline CSPE & - & $2.0-6.0$ & $<15$ & $>2 \mathrm{~h}$ & 23 \\
\hline CPE-FAAS & $5-200$ & $1.6-3.8$ & $<2.4$ & $>60 \mathrm{~min}$ & 24 \\
\hline VALLME-FAAS & $10-500$ & $1.8-2.4$ & $<1.8$ & $\leq 10 \mathrm{~min}$ & This work \\
\hline
\end{tabular}

the determination of trace amount of $\mathrm{Pd}$ and $\mathrm{Au}$ in various real samples.

\section{Conclusion}

The determination of chelates of Pd and Au with DDTC by vortex-assisted liquid-liquid microextraction (VA-LLME) prior to FAAS has been investigated. The phase separation occurred efficiently, which resulted in good enrichment factors and low LOD. And owing to the physicochemical characteristics of pelargonic acid, it is easily emulsified with water and phase separation is easily obtained by centrifugation, with stable effect. The enrichment process simple and easy to operate, all the pretreatment process only needs four steps and the proce-dure can be finished within $10 \mathrm{~min}$. The developed method shows good sensitivity and precision.

\section{ACKNOWLEDGEMENTS}

The work was greatly supported by the Medical Neurobiology Key Laboratory of Kunming University of Science and Technology, Basic and Applied Research Project in Yunnan province (2008ZC082M) and the Analysis and Testing Foundation of Kunming University of Science and Technology (No. 2010121)

\section{REFERENCES}

P. Liang, E. Zhao and F. Li, Talanta, 77, 1854 (2009).

C.R.M. Rao and G.S. Reddi, TrAC Trends Anal. Chem., 19, 565 (2000).

E. Helmers, M. Schwarzer and M. Schuster, Environ. Sci. Pollut. Res. Int., 5, 44 (1998)
4. A.N. Ozsezen, M. Eyidogan, A. Turkcan, E. Alptekin, A. Sanli, M. Canakci and I. Kilicarslan, Electron. J. Vehicle Technol., 1, 1 (2009).

5. J.J. Gooding, V.G. Praig and E.A.H. Hall, J. Anal. Chem., 70, 2396 (1998).

6. R. Merget and G. Rosner, Sci. Total Environ., 270, 165 (2001).

7. K. Ravindra, L. Bencs and R. Van Grieken, Sci. Total Environ., 318, 1 (2004).

8. W.G. Ketel and C. Ntebber, Contact Dermat., 7, 331 (1981).

9. E.J. Underwood, Trace Elements in Human and Animal Nutrition, Academic Press, New York, p. 92 (1977).

10. D.L. Tsalev and Z.K. Zaprianov, Atomic Absorption Spectrometry in Occupational and. Environmental Health Practice, CRC Press, Boca Raton, Florida, p. 104 (1985).

11. X. Wen, P. Wu, K. Xu, J. Wang and X. Hou, Microchem. J., 91, 193 (2009).

12. V.A. Lemos, E.M. Gama and A. da Silva Lima, Mikrochim. Acta, 153, 179 (2006)

13. M.S. Bispo, E.S.B. Morte, M.G.A. Korn, L.S.G. Teixeira, M. Korn and A.C.S. Costa, Spectrochim. Acta B, 60, 653 (2005).

14. Q. Jia, X. Kong, W. Zhou and L. Bi, Microchem. J., 89, 82 (2008).

15. L.S.G. Teixeira, M.D. Bezerra, V.A. Lemos, H.C. Santos, D.S. Jesus and A.C.S. Costa, Sep. Sci. Technol., 40, 2555 (2005).

16. A. Stafiej and K. Pyrzynska, Microchem. J., 89, 29 (2008).

17. V. Lemos, R. Dafranca and B. Moreira, Sep. Purif. Tech., 54, 349 (2007).

18. G.D. Matos, E.B. dos Reis, A.C.S. Costa and S.L.C. Ferreira, Microchem. J., 92, 135 (2009).

19. S. Nazari, Microchem. J., 90, 107 (2008).

20. S.L.C. Ferreira, A.S. Queiroz, J.C.R. Assis, M.G.A. Korn and A.C.S. Costa, J. Braz. Chem. Soc., 8, 621 (1997).

21. F.R.P. Rocha, L.S.G. Teixeira and J.A. Nóbrega, Spectrosc. Lett., 42, 418 (2009). (In press).

22. T. A. Kokya and K. Farhadi, 169, 726 (2009).

23. X.J. Zhao, L. He and C.Z. Huang,Talanta, 101, 59 (2012).

24. M. Ghaedi, A. Shokrollahi, K. Niknam, E. Niknam, A. Najibi and M. Soylak, Talanta, 168, 1022 (2009). 